\title{
UTILIZAÇÃO DE ANOS-PADRÃO NO ESTUDO DA VARIABILIDADE PLUVIOMÉTRICA NO MUNICÍPIO DO CRATO / CEARÁ
}

\author{
Juliana Maria Oliveira Silva ${ }^{(a)}$ \\ (a) Departamento de Geografia / Universidade Regional do Cariri, juliana.oliveira@urca.br
}

Eixo 3: Climatologia em diferentes níveis escalares: mudanças e variabilidades

\begin{abstract}
Resumo
As variações anuais de chuvas em municípios do semiárido nordestino podem estar relacionada a efeitos de escalas regional e global através da interface oceano e atmosfera, especificamente nos Oceanos Pacífico e Atlântico. O trabalho pretende analisar a variabilidade pluviométrica do município do Crato/Ceará a partir da escolha de anos-padrão e com isso selecionar anos representativos do padrão Habitual, Seco e Chuvoso, utilizando a série histórica entre 1974-2016. Para cada ano elegido comparou-se com a atuação de eventos de El Niño, La Niña ou Dipolo do Atlântico que possam ter influenciado na distribuição pluviométrica da área. A atuação dos oceanos foi constatada em muitos casos para a ocorrência do padrão pluviométrico observado em cada ano, demonstrando a importância dos oceanos para o monitoramento da distribuição anual das chuvas no município em análise.
\end{abstract}

Palavras chave: Variabilidade, Oceano Pacífico e Atlântico, Anos-Padrão.

\section{INTRODUÇÃO}

A pluviometria constituti um dos mais relevantes elementos do clima para o semiárido brasileiro, visto que a distribuição das chuvas apresenta uma variabilidade tanto no espaço como tempo, tendo uma concentração maior entre 3 a 5 meses no ano. Os reservatórios hídricos dependem da quantidade de chuvas para abastecerem seus níveis, assim como a agricultura, especialmente os pequenos agricultores que necessitam diretamente dessas chuvas para a sua atividade agrícola, onde muitas vezes a produção é para o consumo familiar, sendo o excedente comercializado.

O Ceará, por estar localizado dentro do domínio do clima semiárido, possui uma variação pluviométrica interanual. Zanella (2005) ao abordar as condições climáticas do Ceará afirma que estas são variáveis e complexas, onde a interação de diferentes Centros de Ação e Sistemas Atmosféricos atuam na região juntamente com os fatores locais e regionais, o que influencia na distribuição da precipitação. A autora ressalta essa variação em diferentes domínios de paisagens cearense, enquanto que nas regiões serranas, os índices pluviométricos podem alcançar 1700mm, no sertão, abrangendo a maior parte do território cearense, os valores oscilam entre $850 \mathrm{~mm}$ a $550 \mathrm{~mm}$ anuais, já no litoral, os índices são mais elevados, entre $1100 \mathrm{~mm}$ e $1350 \mathrm{~mm}$ anuais. 
Desde 2012, o Ceará vem passando por um período de seca com chuvas abaixo da normal climatológica, o que tem comprometido o abastecimento doméstico, a agricultura e outros setores que dependem da água. Pereira e Cuellar (2015) analisaram os efeitos de seca de 2012-2014 no baixo curso da principal bacia hidrográfica do Ceará, o rio Jaguaribe, e identificaram o desaparecimento de lagoas e açudes, entre 2009 e 2014, em dois municípios da região (Limoeiro do Norte e Tabuleiro do Norte). Os autores acrescentam os conflitos socioambientais decorrentes desse período de seca: acesso à agua para as empresas instaladas nos perímetros irrigados, enquanto que os pequenos agricultores ficam mais distante dos recursos hídricos, comprometimento do abastecimento doméstico na Região Metropolitana de Fortaleza e as divergências geradas pela agricultura irrigada na Bacia do Jaguaribe (de um lado o agronegócio, e no outro mais de dois milhões de pessoas na Região Metropolitana de Fortaleza que são abastecidas, em grande parte, pelos açudes Orós e Castanhão, localizados na Bacia do rio Jaguaribe), queda da produção da agricultura familiar, entre outros consequências apontadas pelos autores.

Aqui não se pretende discutir a política de gestão hídrica do Estado do Ceará no que concerne a distribuição da água, nem a seca como fenômeno social que contribui significativamente para efeitos ainda mais adversos em anos de chuvas abaixo do esperado. Outros impactos da seca de 2012-2015 enfocando o Nordeste são destacados no documento técnico elaborado por Martins e Magalhães (2015). Os autores realizaram levantamentos de campo intitulado 'Viagens aos Sertões' (um em 2013 e outro em 2015) a fim de se identificarem as repercussões da seca em diversos municípios do semiárido. Dentre os principais impactos apontados por Martins e Magalhães (2015), destaca-se: não há carros-pipas suficientes para abastecer a população, problemas quanto a alimentação e dessendentação do gado, limitação de recursos para implantação de poços e dessalinizadores, êxodo para as sedes municipais, queda na produção de lavouras temporárias e apicultura. E quanto a situação dos recursos hídricos no Ceará em setembro de 2015, segundo Martins e Magalhães (2015), 21 reservatórios estavam secos e 33, no volume morto.

O objetivo deste artigo consta em compreender a variabilidade da precipitação no município do Crato, localizado no sul do Ceará (figura 01), abrangendo um periodo entre 1974-2016 através da escolha de "anos-padrões", e a partir desses dados selecionar um ano representativo do padrão Seco, Chuvoso e Habitual e correlacionar com os fenômenos oceânicos do Oceano Pacífico (El Niño e La Niña) e as Anomalias da Temperatura da Superfície do Mar do Oceano Atlântico (configurando-se em Dipolo Positivo ou Negativo) que possam ter influenciado na distribuição das chuvas anuais. O método utilizado para a seleção de anos-padrão foi o box-plot que segundo Galvani e Luchiari (2005) é uma técnica estatística que permite identificar para os totais mensais de precipitação os valores máximos, os mínimos, a mediana, o primeiro quartil e o terceiro quartil. 


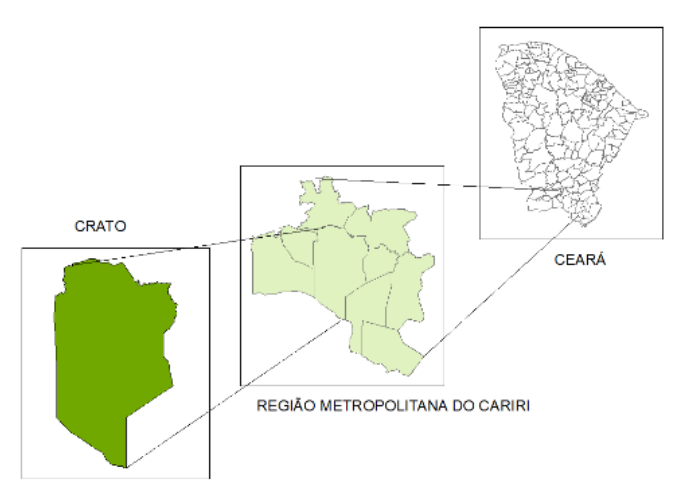

Figura 01: Localização da área de estudo

O conceito de 'ano-padrão' foi preconizado por Monteiro (1971) no artigo intitulado "Análise Rítmica em Climatologia", conferindo aos estudos do clima uma análise mais dinâmica, procurando abordar os fenômenos climáticos para além do uso das técnicas estatísticas. Monteiro (1971, pag.04) afirma: “o conceito de ritmo, expressão da sucessão dos estados atmosféricos, conduz, implicitamente, ao conceito de "habitual", pois que há variações e desvios que geram diferentes graus de distorções até atingir padrões "extremos". Esta metodologia é amplamente utilizada por pesquisadores que procuram evidenciar um caráter mais rítmico em suas pesquisas climatológicas. Para Monteiro (1971) é fundamental que ocorra uma abordagem de valores extremos em confronto com as abstrações médias.

\section{MATERIAL E MÉTODOS}

Algumas metodologias foram desenvolvidas para se estabelecer critérios para escolha de anos-padrão, com destaque para Tavares (1976), um dos primeiros autores a conceber essa proposta. Tendo como referência o conceito de clima proposto por Sorre (1951) e as proposições de Monteiro (1971) da análise rítmica, Tavares (1976) conceituou o que seria um ano padrão "normal”, "seco" e "chuvoso", e ainda formulou um método baseado na estatística para as classificações dos anos-padrão, organizando os valores de precipitação em períodos trimestrais, calculando-se a média e o desvio percentual. 
Segundo Tavares (1976) ano padrão "normal" seria aquele em que a distribuição da precipitação anual é próximo à posição das precipitações médias, um ano padrão "seco" caracteriza-se por valores de precipitações com grande desvio em relação aos dados médios, e o ano padrão "chuvoso" com divergências ao excesso de chuva em relação aos dados mais regulares. Tavares (1976, p.81) afirma que:

"a utilização dos anos padrões na realização da análise rítmica possibilita a compreensão e caracterização do clima, através da análise dos padrões normais e das possiveis diversificações que ocorrem na circulação atmosférica, e que refletem nos tipos de tempo dos anos 'secos' e 'chuvoso'. (TAVARES, 1976:81)".

Outra técnica utilizada para a determinação dos ano-padrão é o box-plot. Entre os autores que já utilizaram este método citam-se os trabalhos de Galvani e Luchiari (2005) que aplicaram para Piracicaba/SP e Schneider e Silva (2014) na microrregião de Dourados/MS.

Os dados pluviométricos utilizados na pesquisa correspondem a série histórica entre os anos de 1974-2016 disponível no site da Fundação Cearense de Meteorologia e Recursos Hídricos (FUNCEME) do Estado do Ceará. O posto "Crato-Crato" está localizado nas coordenadas -7.23 LAT e -39.41 LONG. Os dados são fornecidos em formato de "txt" no bloco de notas e, posteriormente, foram transportados para o formato Excel e organizados e tabulados para os cálculos da estatística básica como a média anual e mensal da série histórica.

As informações de intensidade do El Niño e da La Niña para o período estudado foram obtidos no site do CPTEC/INPE que o dividem em Forte, Moderado e Fraco e da bibliografia disponível em artigos como Nóbrega e Cardoso (2014), além do site do NOAA (National Oceanic e Atmospheric Administration) que também divulga o Índice de Intensidade do Niño (ONI) e da La Niña por trimestre desde 1954. Na homepage da Funceme consultou-se os anos de ocorrência do Dipolo do Atlântico, além da bibliografia existente.

O El Niño é o aquecimento das águas no Pacífico Tropical da Costa Oeste do Peru/Equador até o Oeste do Pacífico, a La Niña é o fenômeno oposto, ou seja, um resfriamento anômalo das águas, conforme Cirilo et al (2007). Esse aquecimento ou resfriamento acabam por alterar o posicionamento da Célula de Walker. Segundo Cirilo et al (2007) em tempos de El Niño ou La Niña a comportamento do oceano e as repercussões na atmosfera se dão da seguinte forma:

"Em anos de El Niño a pressão atmosférica tende a valores mais baixos no Pacífico, ocorrendo um aumento da evaporação no Pacífico, e com a mudança dos ventos alísios ocorre um aumento de movimentos ascendentes e formação de nuvens produzindo chuvas. Esses movimentos ascendentes também favorecem o movimento descendente inibindo a formação de chuvas em outras partes da atmosfera tropical. Esses movimentos descendentes ocorrem justamente no Nordeste do Brasil e na Indonésia, alterando os níveis de precipitação. Em anos de La Niña com o resfriamento das águas, ocorrem um aumento de pressão. Esses níveis altos criam uma forte subsidência inibindo 
a formação de nuvens, mas também produzem movimentos ascendentes no Nordeste do Brasil e sobre a Indonésia (CIRILO, et al 2007: 50-51)”.

Outro fenômeno oceânico atuante que pode influenciar nas chuvas no Nordeste é o padrão Dipolo. O Dipolo do Atlântico refere-se a diferença entre a anomalia da Temperatura da Superfície do Mar-TSM na Bacia do Oceano Atlântico Norte e na bacia do Oceano Atlântico Sul, se for Positivo é desfavorável às chuvas no Nordeste, se for Negativo é favorável (FERREIRA E MELO, 2005).

A construção do gráfico Box-Plot foi realizada através do software Action Stat Pro 3.0. Os dados gerados pelo gráfico são destacados por Galvani e Luchiari (2005) e resumidos na tabela I: O valor máximo (V.máx) é o maior valor encontrado dentro da série. O valor mínimo (Vmín) é o menor valor encontrado. O primeiro quartil está situado entre o (V.mín) e a mediana indicando meses secos (no trabalho adotou-se anos secos). O segundo quartil pode ser chamado de mediana, ou seja, que define a posição central da série, classificado como ano Habitual. Já o terceiro quartil está situado entre a mediana e o (V.máx) indicando meses chuvosos (no trabalho adotou-se ano chuvoso). Galvani e Luchiari (2005) recomendam, assim como também foi utilizado por Schneider e Silva (2014), um range de 5 a 95\% da série, onde os meses em que estiverem entre os 5\% menores serão considerados super-secos e os meses com 5\% entre os maiores serão classificados como chuvosos.

Tabela I: Intervalo de classificação para os anos-padrões

\begin{tabular}{|l|l|}
\hline \multicolumn{1}{|c|}{ PRECIPITAÇÃO ANUAL } & \multicolumn{1}{c|}{ CLASSIFICAÇÃO } \\
\hline $5 \%$ Menores da série & Super-secos \\
\hline $5 \%$ Maiores da série & Super-úmidos \\
\hline Entre o (V. mín) e o $1^{\circ}$ Quartil & Secos \\
\hline Entre o $1^{\circ}$ e $3^{\circ}$ Quartil & Normal /Habitual \\
\hline Entre o $3^{\circ}$ Quartil e o (V. máx) & Úmido / Chuvoso \\
\hline
\end{tabular}

Fonte: Galvani e Luchiari (2005)

\section{RESULTADOS}

A figura 02 ilustra a distribuição das chuvas ao longo da série histórica estudada e com média observada em torno de $1103 \mathrm{~mm}$ anuais. Observa-se a variação das chuvas ao longo dos anos com valores acima da média histórica, anos abaixo da média histórica e outros próximos a média pluviométrica. Destaca-se os anos de 1985 e 2011 classificados como Muito Chuvoso e 1993 e 2012 como Muito Seco.

A figura 03 representa a distribuição mensal das chuvas. Os meses com maiores concentrações de chuvas são de janeiro-maio. A partir de fevereiro até maio tem-se a atuação da Zona de Convergência Intertropical influenciando as chuvas na região, condições observadas por Silva et al (2014) e Brito e Silva (2012) nas pesquisas sobre a hidroclimatologia das bacias hidrográficas no Crajubar (Crato, Juazeiro do 


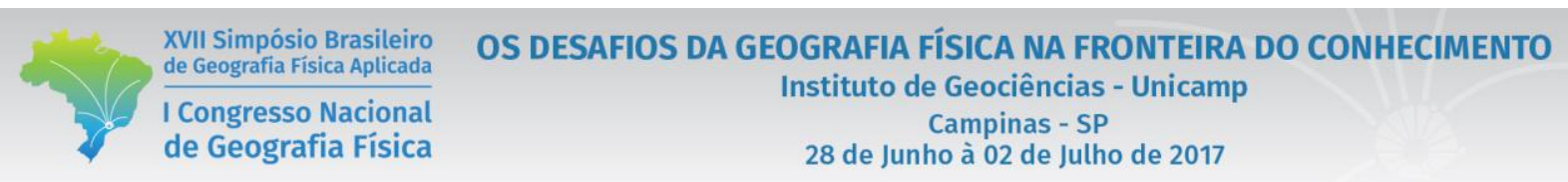

Norte e Barbalha). Soares (2015) evidencia a atuação da ZCIT para todo o Estado do Ceará iniciando no mês de fevereiro, porém sua influência maior nas chuvas acontece nos meses de março, abril e maio.

No Ceará a pré-estação chuvosa tem início em meados de dezembro e janeiro, sendo no Cariri onde as chuvas se iniciam, conforme observado por Brito e Silva (2012) e Soares (2015). O mês de março no Município de acordo com a série histórica é o mais chuvoso com 258,4mm, período de grande atuação da ZCIT no estado. Zanella (2005) comenta que a precipitação do Ceará, além da variação no espaço, apresenta uma variabilidade no decorrer do ano, com um período curto e irregular, e um período mais seco prolongado. Destaca-se em janeiro a atuação de outros fenômenos atmosféricos como os Vórtices Ciclônicos de Altos Niveis contribuindo para a ocorrência das chuvas. Soares (2015) ressalta que os VCAN's associado a MEC (Massa Equatorial Continental) e as Repercussões de Frente Fria (RFF) contribuem para as chuvas de pré-estação no Estado.

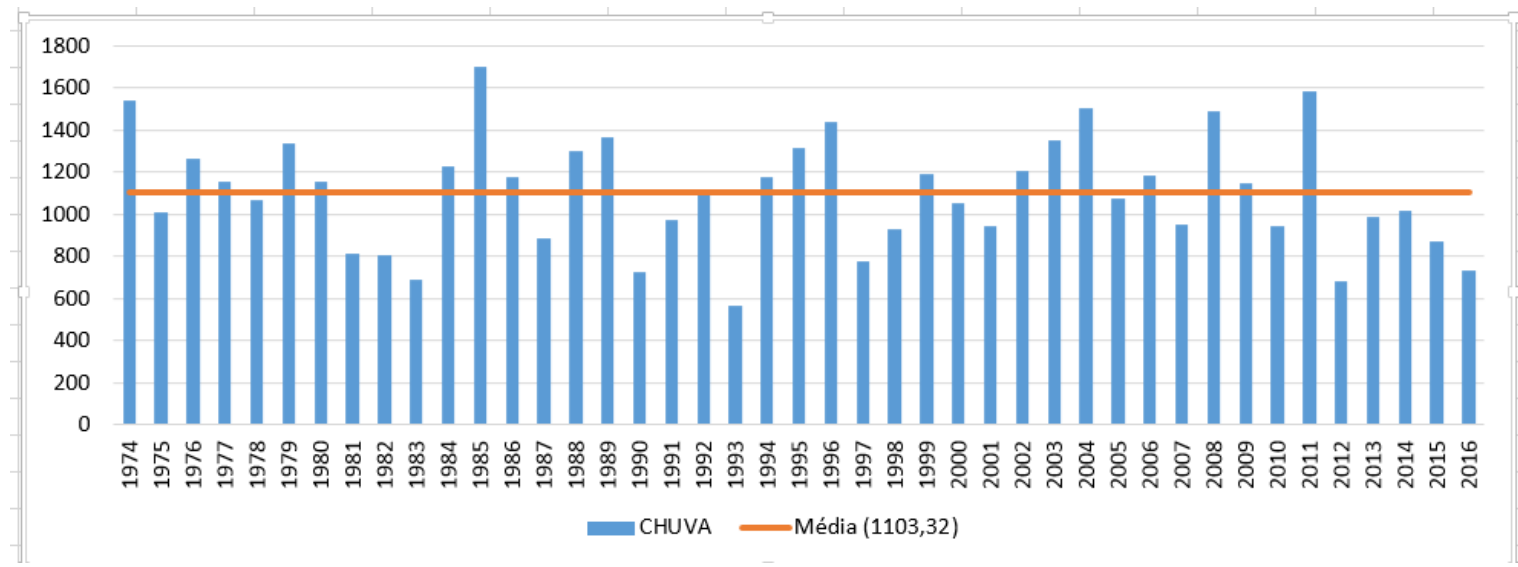

Figura 03: Distribuição do total anual de chuva do Município do Crato/CE

Fonte: Organização própria com base nos dados pluviométrico da Funceme, 2017.

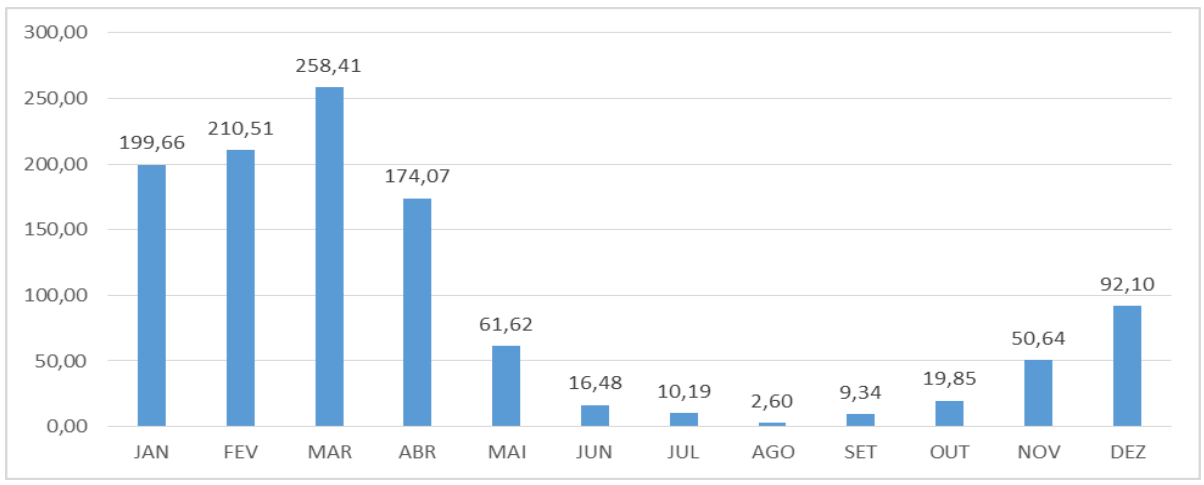

Figura 03: Distribuição da média pluviométrica mensal do Município do Crato/CE Fonte: Organização própria com base nos dados pluviométrico da Funceme, 2017. 


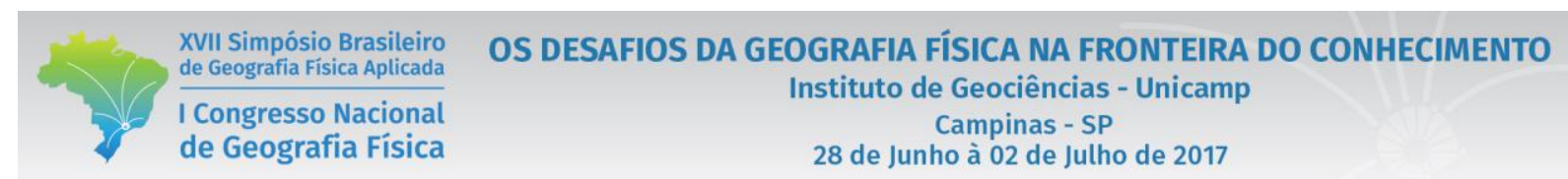

A tabela II indica a classificação dos anos-padrão conforme a técnica do Box Plot. Na série analisada entre 1974-2016: 21 se enquadraram na categoria 'Habitual', 09 anos na categoria 'Seco', 09 no padrão 'Chuvoso', 2 anos em 'Muito Chuvoso' e 02 na categoria 'Muito Seco'. O intervalo estabelecido pelo Box-Plot foi distribuído da seguinte forma: 5\% maiores (02 anos - 1985 e 2011), 5\% menores (02 anos 1993 e 2012), Ano Seco (Valor mínimo e $1^{\circ}$ Quartil: 691mm - 942,2mm), Ano Habitual (1º $3^{\circ}$ Quartil: 942,2mm - 1263mm) e Ano Chuvoso ( $3^{\circ}$ Quartil e Valor máximo: $1263 \mathrm{~mm}$ - 1543mm).

Tabela II - Classificação do padrão pluviométrico anual na área de estudo

\begin{tabular}{|c|c|c|c|c|c|}
\hline ANOS & PRECIPITAÇÃO & CLASSIFICAÇÃO & ANOS & PRECIPITAÇÃO & CLASSIFICAÇÃO \\
\hline 1974 & 1543 & Chuvoso & 1995 & 1313,2 & Chuvoso \\
\hline 1975 & 1012 & Habitual & 1996 & 1438,1 & Chuvoso \\
\hline 1976 & 1263 & Habitual & 1997 & 773,2 & Seco \\
\hline 1977 & 1157 & Habitual & 1998 & 931,4 & Seco \\
\hline 1978 & 1071,2 & Habitual & 1999 & 1192,7 & Habitual \\
\hline 1979 & 1335,1 & Chuvoso & 2000 & 1055,3 & Habitual \\
\hline 1980 & 1152 & Habitual & 2001 & 942,1 & Habitual \\
\hline 1981 & 811 & Seco & 2002 & 1204,8 & Habitual \\
\hline 1982 & 808 & Seco & 2003 & 1350,8 & Chuvoso \\
\hline 1983 & 691 & Seco & 2004 & 1503,9 & Chuvoso \\
\hline 1984 & 1230 & Habitual & 2005 & 1073,9 & Habitual \\
\hline 1985 & 1700 & Muito Chuvoso & 2006 & 1187,9 & Habitual \\
\hline 1986 & 1175,9 & Habitual & 2007 & 953,3 & Habitual \\
\hline 1987 & 888 & Seco & 2008 & 1488,1 & Chuvoso \\
\hline 1988 & 1301,2 & Chuvoso & 2009 & 1150 & Habitual \\
\hline 1989 & 1367 & Chuvoso & 2010 & 943,1 & Habitual \\
\hline 1990 & 726 & Seco & 2011 & 1588,4 & Muito Chuvoso \\
\hline 1991 & 971 & Habitual & 2012 & 678,2 & Muito Seco \\
\hline 1992 & 1119,5 & Habitual & 2013 & 986,6 & Habitual \\
\hline 1993 & 568,1 & Muito Seco & 2014 & 1016,7 & Habitual \\
\hline 1994 & 1175,3 & Habitual & 2015 & 873,3 & Seco \\
\hline & & & 2016 & 732,7 & Seco \\
\hline
\end{tabular}

Fonte: Organização própria com base nos resultados do gráfico Box-Plot

A fim de se compreender essa variabilidade pluviométrica no município verificou-se as condições oceânicas de cada ano no que se refere a atuação de eventos de El Niño, La Niña no Oceano Pacífico e o Dipolo do Atlântico. Após a geração do gráfico do Box-Plot e da classificação dos anos da série histórica, 
escolheu-se um ano representativo para o padrão Habitual, Seco e Chuvoso e comparou-se com os dados de ocorrência de cada evento oceânico, com base nessas informações coletadas discute-se abaixo o padrão da pluviosidade na área de estudo.

Ano Padrão Muito Seco: Os anos considerados "Muito Seco" foram 1993 com 568mm e 2012 678,2mm. Observando a tabela III de atuação de El Niño, La Niña e Dipolo (positivo ou negativo) do Atlântico, o El Niño em 1993 foi classificado como Forte e o Dipolo estava neutro, apresentando então uma influência do ENSO na distribuição pluviométrica no município. Em 2012 o ONI (Índice de Intensidade do Niño) indicava no primeiro trimestre do ano uma La Niña fraca, mas a Anomalia da Temperatura da Superfície do Mar do Atlântico apresentou um Dipolo Positivo, o que influenciou bem mais na configuração de um ano extremamente seco no município.

Ano Padrão Muito Chuvoso: Os anos de 1985 (1700mm) e 2011 (1588,4mm) foram classificados como 'Muito Chuvoso'. Nesses dois anos houve uma atuação do Dipolo do Atlântico, sendo que a La Niña em 2011 estava Moderada. Segundo Ferreira e Melo (2005) quando a La Niña ocorre conjuntamente com o Dipolo Negativo, os anos podem ser Normais, Chuvosos ou Muito Chuvosos, padrão esse encontrado para 2011. Em 2011 foi registrado um evento extremo na cidade no dia 28 de janeiro, com um total de $162 \mathrm{~mm}$ durante a madrugada, e como principais repercussões no espaço identificados por Brito e Silva (2012) foi a estrutura do canal do rio Granjeiro danificada que inundou diversas residências ao longo do canal, o centro da cidade com a entrada da água em vários estabelecimentos, além do acesso a alguns distritos ficaram interditados.

Ano Padrão Chuvoso: Em relação aos anos 'Chuvosos' (1974, 1979, 1988, 1989, 1995, 1996, 2003, 2004, 2008) escolheu-se o ano de 2004 como representativo desta categoria. Em 2004 o município apresentou um total de 1503,8 mm. Neste ano, tanto o El Niño (até o meio do ano), La Niña e o Dipolo do Atlãntico encontrava-se neutro, mas foi um ano com um grande volume de chuvas, especialmente nos meses de janeiro e fevereiro para todo o Estado do Ceará. No município, o mês de Janeiro apresenta uma média de 199,6mm, mas em 2004 choveu 509,1 mm, mais do que o dobro da série histórica. A explicação para o excesso de chuvas em janeiro foi discutida por Alves et 1 (2004), segundo os autores:

"Os ventos alísios de nordeste adjacente à costa norte/nordeste da América do Sul, ficaram mais intensos do que os alísios de sudeste nas proximidades da costa leste do NEB, impulsionando a ZCIT a atingir o setor norte do NEB. Além disso, ocorreu uma interação de quatro sistemas atmosféricos: a ZCIT, a presença de VCAS, a incursão das Frentes Frias para o centro-sul do NEB e influência da Oscilação 30-60 dias. Essa interação associou-se ao estabelecimento da ZCAS ao norte de sua posição climatológica, potencializando a persistência das chuvas no centro-norte do NEB durante o mês de janeiro de 2004. (ALVES, et al 2006: 73)."

Em Fevereiro a média registrada fica em torno de 210,5mm, e em 2004, o volume de chuvas também ultrapassou a média com um acumulado de $474 \mathrm{~mm}$, considerado o mês de Fevereiro mais chuvoso da 
série histórica. Destaca-se também um evento extremo ocorrido nesse mesmo mês no município, especificamente, no dia 16 choveu $156 \mathrm{~mm}$ no posto Crato e no posto Dom Quintino, localizado no distrito de mesmo nome, o volume de chuvas foi de $290 \mathrm{~mm}$, identificada como a maior chuva em $24 \mathrm{~h}$ para a série histórica da área de estudo e também para o Estado.

Ano Padrão Seco: Os anos 'Secos' (1981, 1982, 1983, 1987, 1990, 1997, 1998, 2015 e 2016) escolheu-se como representativo os dois últimos anos 2015/2016. O El Niño no início de 2015 teve sua configuração classificado como fraco, mas aproximadamente em junho passou para Moderado e foi se intensificando ao longo do ano e adentrando 2016. No início da quadra chuvosa do município em 2016 já estava na categoria Forte. As chuvas nesses dois anos estudados apresentaram-se abaixo da média com 873,3mm em 2015 e 732mm para 2016. Apesar de 2016 ter tido forte influência do El Niño no começo do ano, em janeiro as chuvas $(323 \mathrm{~mm})$ ficaram acima da média. A explicação para isso foi a atuação de um sistema meteorológico que costuma atuar na região, o Vórtice Ciclônico de Altos Níveis, que proporciou muitas chuvas durante a sua atuação, pois o município estava na borda desse sistema, e no dia 22 de janeiro em $24 \mathrm{~h}$ choveu $108 \mathrm{~mm}$, causando alagamentos e inundações na cidade. Segundo Cirilo et al (2007), a atuação do VCAS se dá de forma muito irregular, já que esses sistemas, na dependência de seu posicionamento, podem produzir tanto chuvas intensas como seca. Depois da dispersão do Vórtice, as chuvas começaram a diminuir, e em fevereiro, quando se dá o início da atuação da Convergência Intertropical, como o El Niño estava intensificado, as chuvas ficaram em torno de apenas $38,1 \mathrm{~mm}$, demonstrando o quanto 2016 foi afetado por esse fenômeno oceânico.

Ano Padrão Habitual: Dentre os anos 'Habituais' (1975, 1976, 1977, 1978, 1980, 1984, 1986, 1991, 1992, 1994, 1999, 2000, 2001, 2002, 2005, 2006, 2007, 2009, 2010, 2013 e 2014), escolheu-se para análise o ano 2009. Apesar de convencionalmente este ano ser considerado 'Muito Chuvoso' no Ceará, para o Cariri foi classificado como um ano 'Normal', com $1150 \mathrm{~mm}$, pouco mais do que a média (1103mm). Ressalta-se que foi um ano com Dipolo Negativo o que influenciou bastante as chuvas no Estado, tanto que para outros municípios foi considerado um ano extremamente 'Chuvoso', como foi o caso de Fortaleza, segundo os estudos de Soares (2015). O autor explica que em janeiro de 2009 as condições atmosféricas para o Cariri foram favorecidas pela atuação conjunta dos VCAN com as Repercussões de Frentes Frias (RFF), em março teve a atuação da ZCIT no sul do estado, mas em abril este sistema diminuiu um pouco a sua participação, atuando mais ao centro-norte do Ceará. A tabela III resume as informações sobre a classificação dos anos para a área de estudo, bem como a ocorrência dos fenômenos oceânicos e suas intensidades ao longo da série histórica.

Tabela III - Classificação do padrão pluviométrico e condições oceânicas para cada ano da área de estudo 


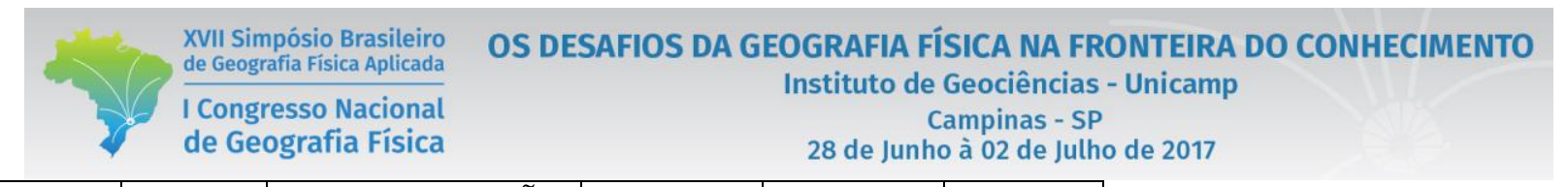

\begin{tabular}{|c|c|c|c|c|c|}
\hline ANOS & TOTAL & CLASSIFICAÇÃO & El niño & La Ninã & Dipolo \\
\hline 1974 & 1543 & Chuvoso & Neutro & Forte & Negativo \\
\hline 1975 & 1012 & Habitual & Fraco & Forte & Neutro \\
\hline 1976 & 1263 & Habitual & Fraco & Forte & Neutro \\
\hline 1977 & 1157 & Habitual & Fraco & Neutra & Negativo \\
\hline 1978 & 1071,2 & Habitual & Fraco & Neutra & Positivo \\
\hline 1979 & 1335,1 & Chuvoso & Fraco & Neutra & Positivo \\
\hline 1980 & 1152 & Normal & Fraco & Neutra & Positivo \\
\hline 1981 & 811 & Seco & Neutro & Neutra & Positivo \\
\hline 1982 & 808 & Seco & Forte & Neutra & Neutro \\
\hline 1983 & 691 & Seco & Forte & Fraca & Positivo \\
\hline 1984 & 1230 & Habitual & Neutro & Fraca & Negativo \\
\hline 1985 & 1700 & Muito Chuvoso & Neutro & Fraca & Negativo \\
\hline 1986 & 1175,9 & Habitual & Moderado & Neutra & Negativo \\
\hline 1987 & 888 & Seco & Moderado & Neutra & Neutro \\
\hline 1988 & 1301,2 & Chuvoso & Moderado & Forte & Negativo \\
\hline 1989 & 1367 & Chuvoso & Neutro & Forte & Negativo \\
\hline 1990 & 726 & Seco & Forte & Neutra & Neutro \\
\hline 1991 & 971 & Habitual & Forte & Neutra & Negativo \\
\hline 1992 & 1119,5 & Habitual & Forte & Neutra & Positivo \\
\hline 1993 & 568,1 & Muito Seco & Forte & Neutra & Neutro \\
\hline 1994 & 1175,3 & Habitual & Moderado & Neutra & Negativo \\
\hline 1995 & 1313,2 & Chuvoso & Moderado & Fraca & Negativo \\
\hline 1996 & 1438,1 & Chuvoso & Neutro & Fraca & Negativo \\
\hline 1997 & 773,2 & Seco & Forte & Neutra & Positivo \\
\hline 1998 & 931,4 & Seco & Forte & Neutra & Neutro \\
\hline 1999 & 1192,7 & Habitual & Neutro & Moderada & Negativo \\
\hline 2000 & 1055,3 & Habitual & Neutro & Moderada & Negativo \\
\hline 2001 & 942,1 & Habitual & Neutro & Neutra & Neutro \\
\hline 2002 & 1204,8 & Habitual & Moderado & Neutra & Negativo \\
\hline 2003 & 1350,8 & Chuvoso & Moderado & Neutra & Negativo \\
\hline 2004 & 1503,9 & Chuvoso & Fraco & Neutra & Neutro \\
\hline 2005 & 1073,9 & Habitual & Fraco & Neutra & Positivo \\
\hline 2006 & 1187,9 & Habitual & Fraco & Neutra & Neutro \\
\hline 2007 & 953,3 & Habitual & Fraco & Forte & Positivo \\
\hline 2008 & 1488,1 & Chuvoso & Neutro & Forte & Negativo \\
\hline 2009 & 1150 & Habitual & Fraco & Neutra & Negativo \\
\hline 2010 & 943,1 & Habitual & Fraco & Neutra & Neutro \\
\hline 2011 & 1588,4 & Muito chuvoso & Neutro & Moderada & Negativo \\
\hline 2012 & 678,2 & Muito Seco & Neutro & Fraca & Positivo \\
\hline
\end{tabular}




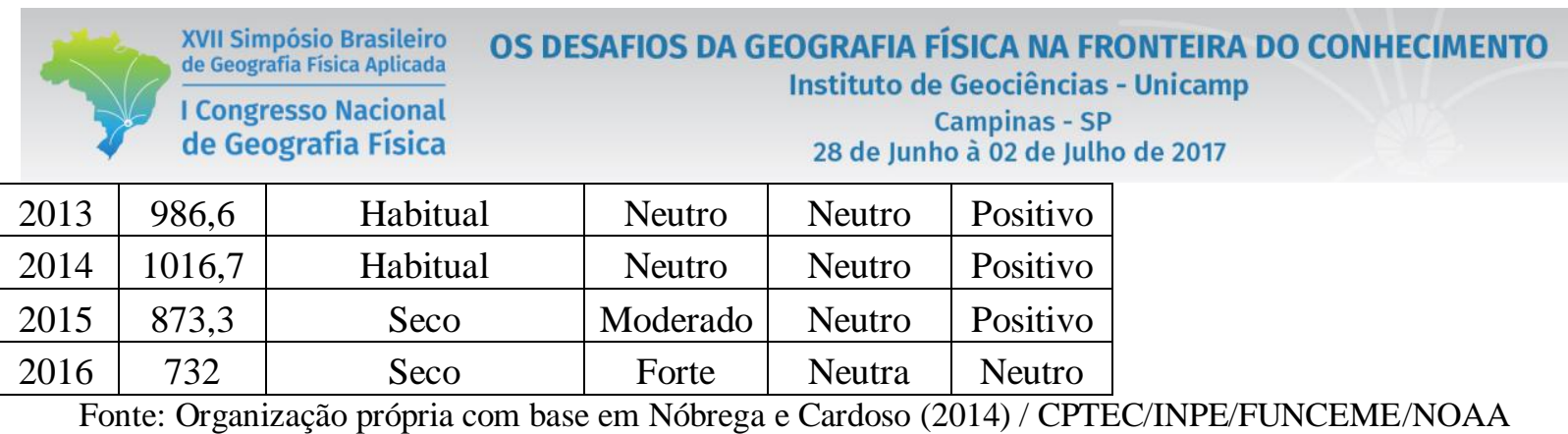

\section{CONSIDERAÇÕES FINAIS}

A técnica do Box-Plot se mostrou válida para a seleção dos anos-padrão para o município do Crato. Nesta primeira aproximação sobre a variabilidade no município, optou-se em trabalhar com os totais anuais de precipitação e não na escala de distribuição mensal das chuvas, conforme sugere Tavares (1977) e Monteiro (1971). De início o objetivo do trabalho consta em analisar como os fenômenos de ordem oceânica contribuem para as chuvas anuais no município estudado.

Apesar dos últimos 5 anos (2012-2016) ser caracterizado como seca para todo o estado, esta não se distribui de uma forma homogênea, fato observado que para o Crato, os anos de 2013 (986,6mm) e 2014 (1016,7mm) foram considerados 'Habituais', mas de uma forma geral, para esses últimos cinco anos, 2012 foi um ano Muito Seco e 2015/2016 anos Seco, indicando ainda a predominância de um padrão mais seco com precipitações abaixo do esperado.

Na série observou-se que o máximo período de repetição do padrão 'Seco’ foi de 1981-1983, influenciado pelo Dipolo Positivo em 1981 e El Niño de categoria Forte em 1982 e 1983. Nos anos de 1990-1993 o El Niño também foi considerado Forte, porém somente os anos de 1990 (726mm) foi considerado Seco e 1993 (568mm) como Muito Seco. Para o ano de 1991 (971 mm) e 1992 (1119,5mm) o El Niño não foi suficiente para causar um padrão 'Seco', sendo classificado esses anos no padrão 'Habitual', o que pode reforçar o que Nóbrega e Santiago (2014) citando os trabalhos de Aragão (1998) e Melo (1999) de que nem todo El Niño pode trazer seca. Pelo menos no município analisado, esses dois anos de atuação do El Niño, não se configurou em anos Secos. O que poderia explicar o ano de 1991 ser classificado como 'Habitual' em tempos de El Niño, é que o Dipolo do Atlântico estava negativo (favorável às chuvas). Já para 1992 tanto o El Niño como o Dipolo (Positivo) não estavam favoráveis as chuvas, mas foi um ano com precipitações em torno da média, necessitando de estudos mais aprofundados para explicar essa dinâmica climática.

Diante dessas nuances que se configuram ano a ano, bem como a distribuição da variável mês a mês, aborda-se aqui a necessidade da ampliação dessa pesquisa para uma abordagem de escala mensal a fim de se elucidar questões mais complexas sobre a variabilidade pluviométrica que o município apresentou. Dos 
anos analisados, a maioria se enquadrou no padrão Habitual (19), intercalando com períodos 'Secos' ou

'Chuvosos'. Percebeu-se que os oceanos contribuem para a ocorrência de anos 'Seco' ou 'Chuvoso', ressaltando a importância que se tem dos estudos sobre o controle climático que os oceanos apresentam para o padrão de chuvas no semiárido brasileiro.

\section{Bibliografia}

ALVES, J. M. B; FERREIRA, F.F; CAMPOS, J. N. B; SOUZA, E. B; DURAN, B. J. ; SERVAIN, J; STUDART, T.M.C. Mecanismos Atmosféricos Associados à Ocorrência de Precipitação Intensa sobre o Nordeste do Brasil durante Janeiro/2004. Revista Brasileira de Meteorologia. Cachoeira Paulista - SP, v. v.21, n.no.1, p. 1-21, 2006.

BRITO, D.S ; SILVA, J. M. O. Estudo dos impactos pluviométricos e os eventos extremos no município do Crato-Ceará. Revista Geonorte, v. Único, p. 964-976, 2012.

CIRILO, J.A; CAMPELlO NETO, M. S. C.; ASFORA, M. C.; MONTENEGRO, S.M.G.L. Caracterização do Semiárido Brasileiro. In: CIRILO, J. A. ; CABRAL, J.J.S.P. ; FERREIRA, J.P.L.; OLIVEIRA, M.J.P.M; LEITÃO, T.E. ; MONTENEGRO, S.M.G.L; GOES, V.C.. (Org.). O Uso Sustentável dos Recursos Hídricos em Regiões Semi-Áridas. 1ed.Porto Alegre: ABRH, 2007, v. 1, p. 33-63.

CPTEC. Centro de Previsão de Tempo e Estudos Climáticos. El Niño e La Niña. Disponível em http://enos.cptec.inpe.br/. Acesso em 20 de novembro de 2016.

FERREIRA, A. G. F.; MELLO, N.G.S. Principais sistemas atmosféricos atuantes sobre a Região Nordeste do Brasil e a influência dos Oceanos Pacífico e Atlântico no clima da região. Revista Brasileira de Climatologia, vol.1, $\mathrm{n}^{\mathrm{o}}$ 1, 2005.

FUNCEME, Fundação Cearense de Meteorologia e Recursos Hídricos. Base de dados pluviométricos. Fortaleza: FORTALEZA. Disponível em <www.funceme.br >. Acesso em 02 de janeiro de 2017.

GALVANI E; LUCHIARI A. Critérios para classificação de anos com regime pluviométrico normal, seco e úmido. São Paulo. Anais do X Encontro de Geógrafos da América Latina, 2005, p. 5701-5710.

MARTINS, E. S. P. R ; MAGALHÃES, A. R. A seca de 2012-2015 no Nordeste e seus impactos. Brasília: Edição Especial Parcerias Estratégicas, v. 20, p. 107-128-128, 2015.

MONTEIRO, C.A.F. Análise Rítmica em Climatologia. Instituto de Geografia, Universidade de São Paulo. São Paulo. 1971.

NOAA. El Niño-Southern Oscillation. Disponível em: http://www.cpc.ncep.noaa.gov/products/analysis_monitoring/ensostuff/ensoyears.shtml. Acesso em: 20/01/2017.

NÓBREGA, R.S; SANTIAGO, G. A. C. F. Tendência de temperatura na superfície do mar nos oceanos Atlântico e Pacífico e a variabilidade de precipitação em Pernambuco. Revista Mercator: Fortaleza. v. 13, p. 107-118, 2014.

PEREIRA, G.R; CUELLAR, M.D.Z. Conflitos pela água em tempos de seca no Baixo Jaguaribe, Estado do Ceará. Estudos Avançados (Online), v. 29, p. 115-137, 2015.

SCHNEIDER, H; SILVA, C. A. O uso do modelo box-plot na identificação de anos padrão Seco, Chuvosos e Habituais na microregião de Dourados, Mato Grosso do Sul. Revista do Departamento de Geografia - USP. v. 27, p. 131-146, 2014. 


\section{OS DESAFIOS DA GEOGRAFIA FÍSICA NA FRONTEIRA DO CONHECIMENTO \\ Instituto de Geociências - Unicamp \\ Campinas - SP \\ 28 de Junho à 02 de Julho de 2017}

SILVA, J. M. O; BRITO, D. S. ; SILVA, M. B. da Aspectos hidroclimatológicos em microbacias hidrográficas: subsídios para o planejamento ambiental. In: Jorn Seemann. (Org.). Recortes Espaciais do Cariri Cearense: contribuições para geografizar a região. 1ed.Fortaleza: RDS, 2014, v. 1, p. 65-94.

SOARES, L.P. Caracterização climática do Estado do Ceará com base nos agentes da circulação regional produtores dos tipos de tempo. Programa de Pós-Graduação em Geografia. Universidade Federal do Ceará. Fortaleza, 2015. Dissertação de Mestrado.

TAVARES, A.C. Critérios de escolha de anos padrões para análise rítmica. Geografia, n.1, v.1, Rio Claro, abril 1976, p.79-87.

ZANELLA, M. E. Caracterização climática e os recursos hídricos do Estado do Ceará. In: SILVA, Z. B. da; DANTAS, E. W.; CAVALCANTE, T. (Org.). Geografia do Ceará: um novo olhar geográfico. 1ed. FORTALEZA - CE: Ed. Demócrito Rocha, 2005, v. 01, p. 169-188. 